\title{
Zooplankton as an early warning system of persistent organic pollutants contamination in a deep lake (lake Iseo, Northern Italy)
}

\author{
Roberta BETTINETTI,${ }^{*}$ Letizia GARIBALDI,${ }^{2}$ Barbara LEONI, ${ }^{2}$ Silvia QUADRONI, ${ }^{1}$ Silvana GALASSI ${ }^{3}$ \\ ${ }^{1}$ University of Insubria, Department of Theoretical and Applied Sciences, Via J.H. Dunant 3, 21100 Varese - Via Valleggio 11, 22100 \\ Como, Italy; ${ }^{2}$ University of Milano-Bicocca, Department of Sciences and Technologies of Environment and Landscape, Piazza della \\ Scienza 1, 20126 Milano, Italy; ${ }^{3}$ University of Milano, Department of Biology, Via Celoria 26, 20133 Milano, Italy. \\ *Corresponding author: roberta.bettinetti@uninsubria.it
}

\begin{abstract}
The lake Iseo has been recently contaminated by DDT residues, originated from the melting of a glacier that released the pollutants accumulated in the past. Because of this recent input, DDT residues concentrations rose more quickly in zooplankton than in fish during 2009. In autumn 2010 the ratio drastically dropped to one-two for all the compounds indicating that the glacial DDT load should have been ceased. The situation was different for PCBs that were released to a much lower extent from glaciers. The PCB 138 ratio between zooplankton and fish was always around one-two in both years. As the zooplankton response to pollution changes resulted particularly prompt, our research highlights the importance of this component as an early warning bioindicator of hydrophobic pollutants.
\end{abstract}

Key words: trophic chain, PCBs, DDTs, biomagnification, bioindicator

Received: January 2012. Accepted: April 2012.

\section{INTRODUCTION}

Since the beginning of ecotoxicology until today, it has become more and more evident that knowledge of the secondary poisoning of organisms is an essential requisite for a proper environmental hazard and risk assessment. At the same time, there has been a steady development of new predictive models to quantify the persistent organic pollutants (POPs) in the aquatic food chains (Mackay and Fraser, 2000). Until recently, the most detailed and discussed assessment efforts in freshwaters have involved the prediction of the bioaccumulation in fish that represent an important part of the human diet. Complete reviews of existing approaches and predictive models can be found in e.g. Mackay and Fraser (2000).

Little is still known on the role of the contaminants transfer from the lowest trophic levels in lakes. The uptake of POPs by phytoplankton is not completely clarified and the variability of field-measured contaminant concentrations is largely responsible for the uncertainty regarding higher trophic levels of bioaccumulation (Glaser and Connolly, 1995). At the second trophic level, zooplankton, an heterogeneous group of organisms typically composed of a prevalence of primary consumers, plays an important ecological role both in controlling the phytoplankton community and as a direct or indirect food source for other aquatic organisms; however, predators are also usually comprised in this second trophic level. Although the role of zooplankton in transferring contaminants to the higher trophic levels is widely recognized (Day, 1990), few mon- itoring studies of pollutants included this component of aquatic biocenoses and very little effort was dedicated to investigate seasonal patterns of contamination of zooplankton in relation to their composition and behaviour. Moreover, the estimate of the chemical concentration in zooplankton is usually made through equilibrium partitioning models (Connolly and Pedersen, 1988; Campfens and Mackay, 1997), although biokinetic parameters of zooplankton (i.e. small size and short life-span) make these organisms very sensitive to pollution events lasting for some weeks or months, such as those deriving from secondary sources. On the other hand, the environmental surveillance should be precisely targeted to detect unexpected events, caused by e.g. human activities.

Recent studies (Bettinetti et al., 2010, 2012) showed that in lake Maggiore (Northern Italy) the Bioaccumulation Factor on lipids $\left(\mathrm{BAF}_{\mathrm{L}}\right)$ values of zooplanktivorous fish for pp'dichlorodiphenyltrichloroethane (pp'DDT), pp'dichlorodiphenyldichloroethylene (pp'DDE) and pp'dichlorodiphenyldichloroethane (pp'DDD) were lower than the corresponding values for zooplankton; this $a p$ parent thermodynamic paradox has been explained supposing that a steady-state condition has not been reached in the lake due to a rather recent input of contaminants from in-lake remobilization of contaminated material or possibly from the polluted industrial site where pp'DDT was produced until 1996. This unexpected finding deserved a more thorough survey, since zooplanktonic species, which are mostly composed by arthropods (crustaceans) like the target insects against which the insecti- 
cides were designed, should be much more negatively affected than the upper trophic levels. Moreover, the prompt response of zooplankton is an essential requirement for bioindicators of pollution by bioaccumulable substances.

Another large southern Alpine lake, lake Iseo (Fig. 1), was recently contaminated by DDT residues, originating in this case from the melting of an high-mountain glacier that released the compounds accumulated in the past after their dramatic retreat caused by global warming (Bettinetti et al., 2008). Sediment analysis allowed to reconstruct the past pollution (Bettinetti et al., 2011) showing that the maximum polychlorinated biphenyl (PCB) concentrations were found in sediment layers corresponding to the 1970s, when the highest production and use of these compounds occurred in Italy. Hexachlorobenzene (HCB) was always present since it still enters the environment mainly as a by-product or impurity of many chemicals processes. Concentrations of DDT residues showed a sharp increase from the early 1990s, long after their agricultural use was banned in Italy. This delayed pollution supported the previous hypothesis of glaciers as a secondary source of pollution (Bettinetti et al., 2008), detected by living bioindicators such as mussels (Dreissena polymorpha) and shad (Alosa agone Scopoli 1976).

In the present work, therefore, water, zooplankton and shad were sampled from summer 2009 to autumn 2010 in lake Iseo, to investigate the evolution of POP contamination after the glacier input and to assess the suitability of zooplankton as an early warning pollutant ring bell in lakes.

\section{METHODS}

\section{Sampling and chemical analysis of organisms and water}

Five L-integrated water samples were collected in the 0-20 $\mathrm{m}$ isothermal layer in summer 2009 (June $29^{\text {th }}$ ) (temperature, $16.5^{\circ} \mathrm{C}$ ) and autumn 2010 (November $24^{\text {th }}$ ) (temperature, $10.8^{\circ} \mathrm{C}$ ) in the deepest point of the lake $\left(45^{\circ} 42^{\prime} 59^{\prime \prime} \mathrm{N}\right.$ and $10^{\circ} 03^{\prime} 41^{\prime \prime} \mathrm{E}$, Fig. 1). At the laboratory, water samples were processed as reported in Bettinetti et al. (2010). In summer (June 29 $9^{\text {th }}$ ) and autumn (October $\left.6^{\text {th }}\right) 2009$ and in summer (June 23 ${ }^{\text {rd }}$ ) and in autumn (November $\left.24^{\text {th }}\right) 2010$, zooplankton were collected in the 0 $20 \mathrm{~m}$ layer with an open net $(25 \mathrm{~cm}$ of diameter, $200 \mu \mathrm{m}$ mesh - rotifers were not included) at the deepest point of the lake by means of vertical tows. The net mesh size facilitated high filtration efficiency, avoiding large phytoplankton colonies and capturing large zooplankton species regarded as the main important link in the transfer of pollutants (Zaret, 1980). Collected zooplankton included Copepoda (Copidodiaptomus steueri in all periods, and Thermocyclops dybowskii, only during summer) and Cladocera (Daphnia hyalina x cucullata x galeata complex, Eubosmina longicornis, Diaphanosoma brachyurum, Leptodora kindtii and Bythotrephes longimanus).
Adult specimens (1-2 years) of shad (Alosa agone Scopoli 1976) were also collected in the same lake area using floating gillnets in summer 2009 (June $29^{\text {th }}$ ) and autumn (November 24 $4^{\text {th }}$ ) 2010. Fish were then stored frozen at $-20^{\circ} \mathrm{C}$. In each sample pp'DDT, pp'DDE, pp'DDD, $\alpha$ hexachlorocyclohexane $(\alpha-\mathrm{HCH})$ and lindane $(\gamma-\mathrm{HCH})$, HCB, PCB 28, PCB 52, PCB 101, PCB 118, PCB 138, PCB 149, PCB 153, PCB 170 and PCB 180 were analyzed by gas chromatography as described in Bettinetti et al. (2010). The detection limit for each POP was $0.005 \mathrm{ng}$ $\mathrm{L}^{-1}$ and $1 \mathrm{ng} \mathrm{g}^{-1}$ lipid weight (1.w.).

Good laboratory practices were tested on the standard reference materials BCR-598 (for OCs) and BCR-349 (for $\mathrm{PCBs})$, respectively, analysing samples in triplicate. The percentage of recovery of pp'DDE was $107.5( \pm 4.0 \%)$, of pp'DDD $106.2( \pm 4.0 \%)$, of pp'DDT $106.2( \pm 3.0 \%)$, of HCHs varied between $89.5( \pm 9.1 \%)$ and $107.7( \pm 7.2 \%)$, of HCB $105.2( \pm 9.9 \%)$, and of PCBs it was within the range $91.3( \pm 1.1 \%)-102.2( \pm 1.6 \%)$.

Since it is hard to have enough quantity of material to perform the analysis of the contaminants in zooplankton, the variability of concentrations among different analyses of the same sample was considered the one previously as-

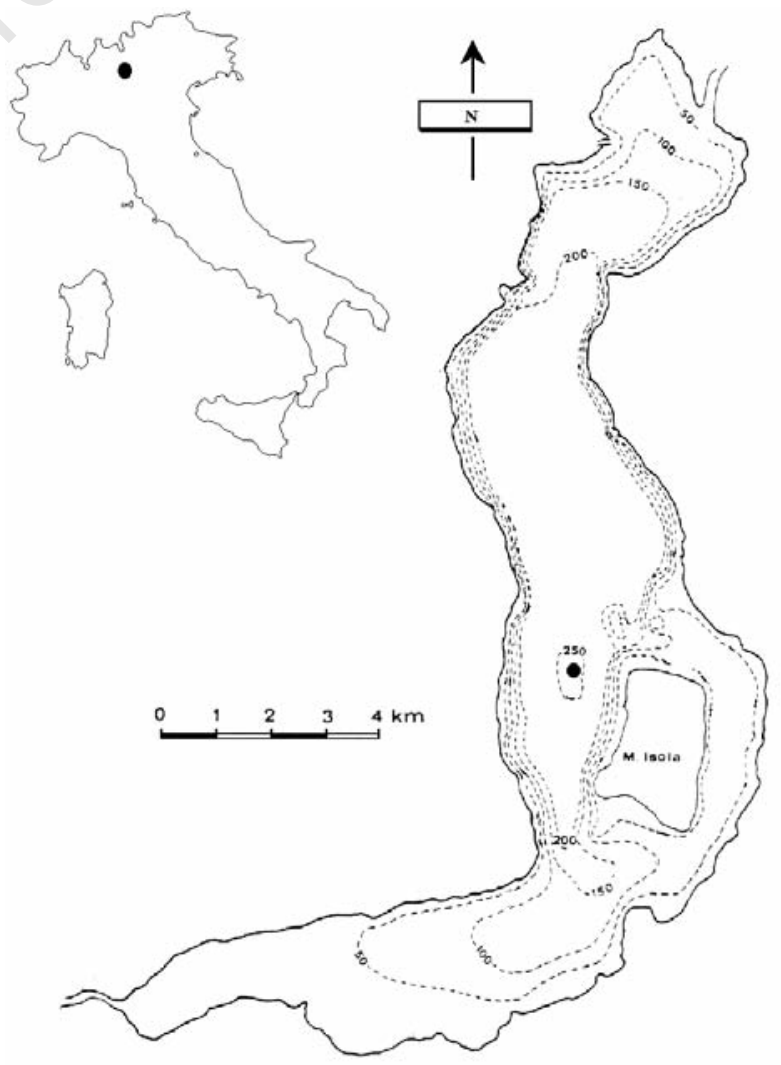

Fig. 1. Lake Iseo and its location in Italy. The black dot on the lake Iseo map indicates the sampling point of zooplankton and fish. 
sessed (Bettinetti et al., 2010): 6.4\% for pp'DDE, 7.3\% for pp'DDD, 5.4\% for pp'DDT, $6.9 \%$ for PCB 138, $11.9 \%$ for $\mathrm{HCB}, 15 \%$ for $\gamma-\mathrm{HCH}$ and $1.4 \%$ for $\alpha-\mathrm{HCH}$, whilst for lipids it was $4.7 \%$.

\section{RESULTS AND DISCUSSION}

As the main aim of this work was to determine the bioaccumulation of POPs in the pelagic community, their concentrations have to be determined both in water and in the biota. In our study, PCB concentrations in water were very low and only PCB 138 could be quantitatively determined; therefore, the latter was taken as the representative component of this complex mixture of PCBs.

Considering the variability of concentrations among different analyses of the same sample (Tab. 1), significant differences $(t$-test, $\mathrm{P}<0.005)$ existed between the two seasonal zooplankton samples within the same year for pp'DDT, pp'DDE and HCB. Moreover significant decreasing trends of concentration were clearly observed from 2009 to 2010 for all DDT compounds $\left(r^{2}\right.$ pp'DDE $=0.92 ; r^{2}$ pp'DDD $=0.80 ; r^{2}$ pp'DDT $\left.=0.72\right)$, and $\mathrm{HCB}\left(\mathrm{r}^{2}=0.67\right) ; \alpha-\mathrm{HCH}$ increased $\left(\mathrm{r}^{2}=0.75\right)$, while $\gamma-\mathrm{HCH}$ and PCB 138 concentrations were not significantly different (Tab. 1).
The most important finding in this two-year study is the change of the concentration ratio between zooplankton and fish, which is about nine-fold for pp'DDE and pp'DDT and seventeen-fold for pp'DDD in summer 2009, and drastically drops to one-two for all these compounds in autumn 2010. The ratio of PCB 138, conversely, is around one-two in both years. $\mathrm{HCB}, \alpha-\mathrm{HCH}$ and $\gamma-\mathrm{HCH}$ ratios are more variable in time, probably because they approached the detection limit of $1 \mathrm{ng} \mathrm{g}^{-1} \mathrm{l}$.w. It is quite clear that in 2009 no biomagnification from zooplankton to fish took place in particular for DDTs. A similar situation was observed in another large southern Alpine lake (lake Maggiore) and was ascribed to a recent input of these compounds which were not distributed in the different environmental compartments as expected in equilibrium conditions (Bettinetti et al., 2012). Even in the case of lake Iseo a recent input of DDTs from secondary sources has been detected (Bettinetti et al., 2008); sediment analyses confirmed that this load, very likely due to the release of contaminants following the melting of glaciers, caused a drastic increase of DDTs from 1991 to 2008, with higher values than those measured during the 1970s, when DDT was largely used in agriculture (Bettinetti et al., 2011).

$\mathrm{BAF}_{\mathrm{L}}$ values in 2009 and 2010 were of the same order of magnitude for all compounds (Tab. 2), with the excep-

Tab. 1. Lipid content (\%) and persistent organic pollutants concentrations (ng g-1 l.w.) in zooplankton and shad in 2009 and 2010. Standard deviations in brackets.

\begin{tabular}{|c|c|c|c|c|c|c|}
\hline & $\begin{array}{c}\text { Summer } \\
\text { Zooplankton }\end{array}$ & $\begin{array}{l}2009 \\
\text { Shad }\end{array}$ & $\begin{array}{c}\text { Autumn } \\
\text { Zooplankton }\end{array}$ & $\begin{array}{c}\text { Summer } \\
\text { Zooplankton }\end{array}$ & $\begin{array}{c}2010 \\
\text { Autumn } \\
\text { Zooplankton }\end{array}$ & Shad \\
\hline Lipid & $8.0(0.2)$ & 3.4 & $12.1(0.6)$ & $10.7(0.5)$ & $8.1(0.4)$ & 8.5 \\
\hline PCB 138 & $170.0(11.7)$ & 151.5 & $200.6(13.8)$ & $94.4(6.5)$ & $104.3(7.2)$ & 77.7 \\
\hline pp'DDE & $3595.3(230.1)$ & 380.0 & $2785.0(178.2)$ & $451.1(28.9)$ & $131.0(8.4)$ & 99.6 \\
\hline pp'DDD & $1383.3(101.0)$ & 81.3 & $1386.9(101.2)$ & $35.6(2.6)$ & $12.6(0.9)$ & 11.6 \\
\hline pp'DDT & $727.7(39.3)$ & 78.0 & $872.3(47.1)$ & $48.7(2.6)$ & $29.5(1.6)$ & 19.7 \\
\hline HCB & $10.3(1.3)$ & 1.5 & $5.1(0.6)$ & $3.3(0.4)$ & $4.3(0.5)$ & 2.6 \\
\hline$\gamma-\mathrm{HCH}$ & $5.4(0.8)$ & 1.3 & $8.9(1.3)$ & $4.5(0.7)$ & $8.6(1.3)$ & 1.3 \\
\hline$\alpha-\mathrm{HCH}$ & $3.3(0.03)$ & 1.4 & $2.9(0.03)$ & $9.7(0.1)$ & $9.4(0.1)$ & 1.9 \\
\hline
\end{tabular}

Tab. 2. $\log \mathrm{K}_{\text {ow }}$ values of the different investigated persistent organic pollutants, their concentrations in water and $\operatorname{LogBAF} \mathrm{F}_{\mathrm{L}}$ of zooplankton and shad in 2009 and 2010.

\begin{tabular}{|c|c|c|c|c|c|c|c|}
\hline & $\log \mathrm{K}_{\mathrm{ow}}$ & $\begin{array}{l}\text { Water } \\
\text { ng L L-1 }\end{array}$ & 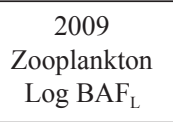 & $\begin{array}{c}\text { Shad } \\
\log \mathrm{BAF}_{\mathrm{L}}\end{array}$ & $\begin{array}{l}\text { Water } \\
\text { ng L L-1 }\end{array}$ & $\begin{array}{c}2010 \\
\text { Zooplankton } \\
{\text { Log } \mathrm{BAF}_{\mathrm{L}}}\end{array}$ & $\begin{array}{c}\text { Shad } \\
\text { Log } \text { BAF }_{L}\end{array}$ \\
\hline PCB138 & 6.83 & 0.031 & 6.74 & 6.69 & 0.081 & 6.11 & 5.98 \\
\hline pp'DDE & 5.70 & 0.056 & 7.81 & 6.83 & 0.09 & 6.16 & 6.04 \\
\hline pp'DDD & 5.50 & bdl & - & - & 0.017 & 5.87 & 5.83 \\
\hline pp'DDT & 6.19 & 0.008 & 7.96 & 6.99 & 0.024 & 6.09 & 5.92 \\
\hline $\mathrm{HCB}$ & 5.80 & 0.085 & 5.08 & 4.25 & 0.075 & 4.75 & 4.55 \\
\hline$\gamma-\mathrm{HCH}$ & 3.80 & 0.078 & 4.84 & 4.21 & 0.192 & 4.65 & 3.82 \\
\hline$\alpha-\mathrm{HCH}$ & 3.70 & 0.070 & 4.67 & 4.31 & 0.084 & 5.05 & 4.35 \\
\hline
\end{tabular}

$K_{\text {ow }}$ Octanol-Water Partition coefficient; $B A F_{L}$, Bioaccumulation Factor on lipids. 
tion of DDTs, whose $\mathrm{BAF}_{\mathrm{L}} \mathrm{s}$ are of one-two order of magnitude higher in 2009 than in 2010. These findings strongly support the existence of a non-equilibrium condition between water and zooplankton in 2009 for DDTs due to their glacial origin. It is very likely that the chemicals adsorbed by algae are quickly replaced by the waterair exchange of contaminants coming from the agricultural and industrial areas in the southern area of the lake. Conversely, DDT residues enter the lake through the northern tributary mainly during the summertime, when ices melt and the portion adsorbed on/by algae cannot be easily replaced by the air burden.

Superficial sediments $(0-2 \mathrm{~cm}$; Bettinetti et al., 2011) can be regarded as representative of the phytoplankton recently settled, as lake Iseo is eutrophic (Garibaldi et al., 2003) and most of the suspended solids should correspond to the algal biomass. Using the Karickoff's equation, which describes the relationships of contaminants in relation to water-particulate matter-sediments (Karickoff, 1981), the expected concentrations of POPs in water at equilibrium were calculated (Supplementary Material). Actually, the measured concentrations of DDT compounds in the upper layer of the waters of lake Iseo were much lower than expected at equilibrium conditions (expected concentrations were: pp'DDE: $4.452 \mathrm{ng} \mathrm{L}^{-1}$, pp'DDD: $0.962 \mathrm{ng} \mathrm{L}^{-1}$, pp'DDT: $0.146 \mathrm{ng} \mathrm{L}^{-1}$ ), while PCB 138 , lindane and $\mathrm{HCB}$ were in a rather good agreement with the calculated values (PCB 138: $0.013 \mathrm{ng} \mathrm{L}^{-1}$, lindane: $0.798 \mathrm{ng} \mathrm{L}^{-1}$; HCB: $0.013 \mathrm{ng} \mathrm{L}^{-1}$ ).

These findings confirm that suspended particles settling to the lake bottom capture DDT homologues from the water and transport them to the sediments without reaching a steady-state condition with water. This phenomenon seems to protect fish from an excessive contamination; therefore, levels of DDTs are lower than those consistent with the human consumption, as reported by Bettinetti et al. (2008). The zooplankton community, instead, seemed to be much more affected because it is mainly composed by herbivores. However, although heavily contaminated, zooplankton organisms may have not been subject to direct negative effects (Bettinetti et $a l ., 2005)$. The general decrease in DDT levels measured in 2010 could probably depend on the diminishing loads of these contaminants accumulated in the past in the ice of glaciers; therefore a gradual depletion of the accumulated contaminants can be reasonably expected. The evident recovery of zooplankton compared to fish in 2010 probably occurred because zooplankton are composed of organisms with a particularly rapid life cycle and the intake/release of contaminants are faster than in fish.
Although POP analysis of fish is crucial to protect human health, even zooplankton should be analyzed in lakes as an early warning system for hydrophobic pollutants and to assess if the different species of the community may be at risk.

\section{ACKNOWLEDGMENTS}

The authors would like to thank Prof. Federico Aligi Pasquarè, University of Insubria, Varese, for the useful suggestions and the English revision of the manuscript.

\section{REFERENCES}

Bettinetti R, Croce V, Galassi S, 2005. Ecological risk assessment for the recent case of DDT pollution in Lake Maggiore (Northern Italy). Water Air Soil Pollut. 162:385-399.

Bettinetti R, Quadroni S, Galassi S, Bacchetta R, Bonardi L, Vailati G, 2008. Is meltwater from Alpine glaciers a secondary DDT source for lakes? Chemosphere 73:1027-1031.

Bettinetti R, Galassi S, Guzzella L, Quadroni S, Volta P, 2010. The role of zooplankton in DDT biomagnification in a pelagic food web of Lake Maggiore (Northern Italy). Environ. Sci. Pollut. Res. 17:1508-1518.

Bettinetti R, Galassi S, Guilizzoni P, Quadroni S, 2011. Sediment analyses to support the recent glacial origin of DDT pollution in Lake Iseo (Northern Italy). Chemosphere 85:163-169.

Bettinetti R, Quadroni S, Manca M, Piscia R, Volta P, Guzzella L, Roscioli C, Galassi S, 2012. Seasonal fluctuations of DDTs and PCBs in zooplankton and fish of Lake Maggiore (Northern Italy). Chemosphere 88:344-351.

Campfens J, Mackay D, 1997. Fugacity-based model of PCB bioaccumulation in complex aquatic food webs. Environ. Sci. Technol. 31:577-583.

Connolly JP, Pedersen CJ, 1988. A thermodynamic based evaluation of organic chemical accumulation in aquatic organisms. Environ. Sci. Technol. 22:99-103.

Day K, 1990. Pesticide residues in freshwater and marine zooplankton: a review. Environ. Pollut. 67:205-222.

Garibaldi L, Anzani A, Marieni A, Leoni B, Mosello R, 2003. Studies on the phytoplankton of the deep subalpine Lake Iseo. J. Limnol. 62:177-189.

Glaser D, Connolly JP. 1995. Uncertainty in bioaccumulation modelling, p. 123. In: Toxic substances in water environments: assessment and control. Proc. Water Environment Federation Specialty Conference.

Karickhoff SW, 1981. Semi-empirical estimation of sorption of hydrophobic pollutants on natural sediments and soils. Chemosphere 10:833-846.

Mackay D, Fraser A, 2000. Bioaccumulation of persistent organic chemicals: mechanisms and models. Environ. Poll. 110:375-391.

Zaret TM, 1980. Predation and freshwater communities. New Haven and London Yale University Press: 187 pp. 